
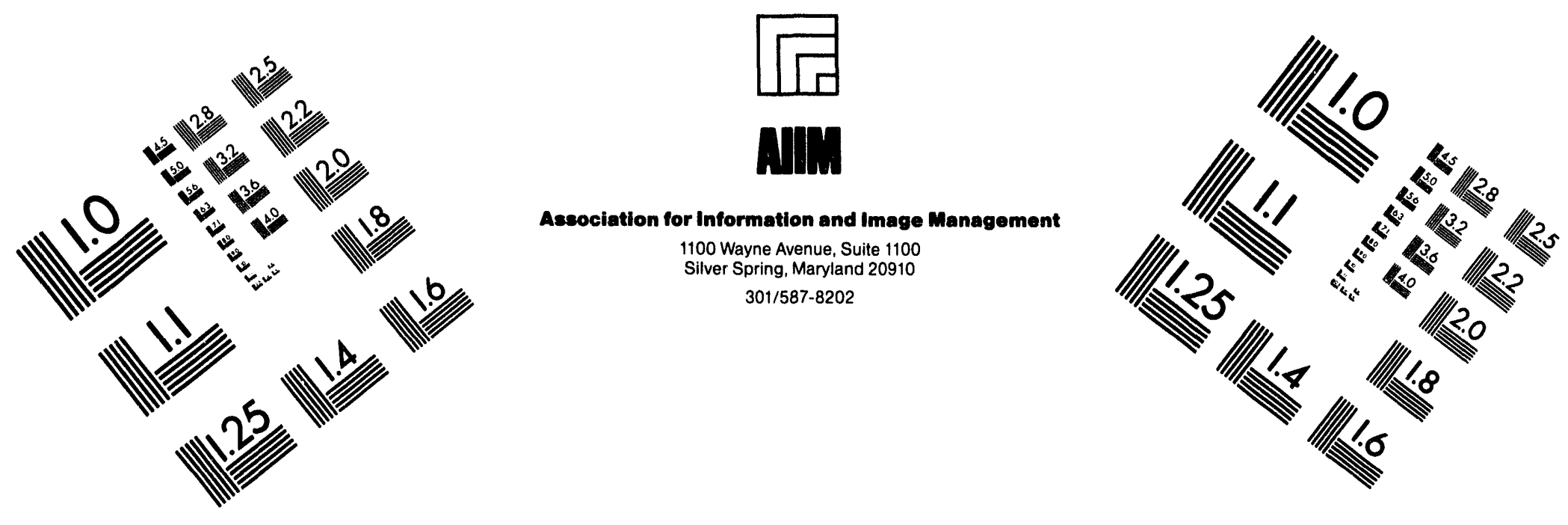

\title{
Centimeter
}

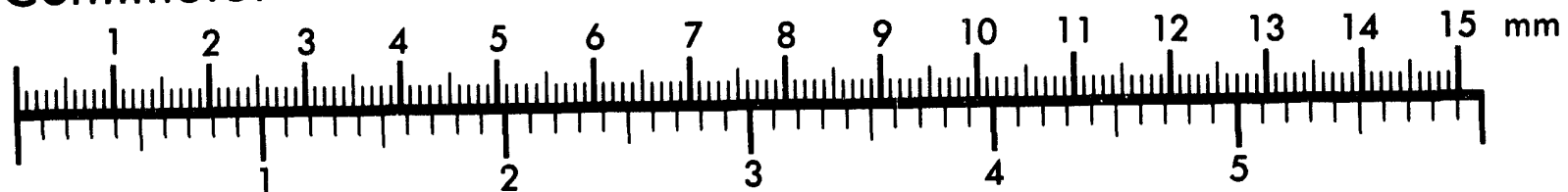
Inches

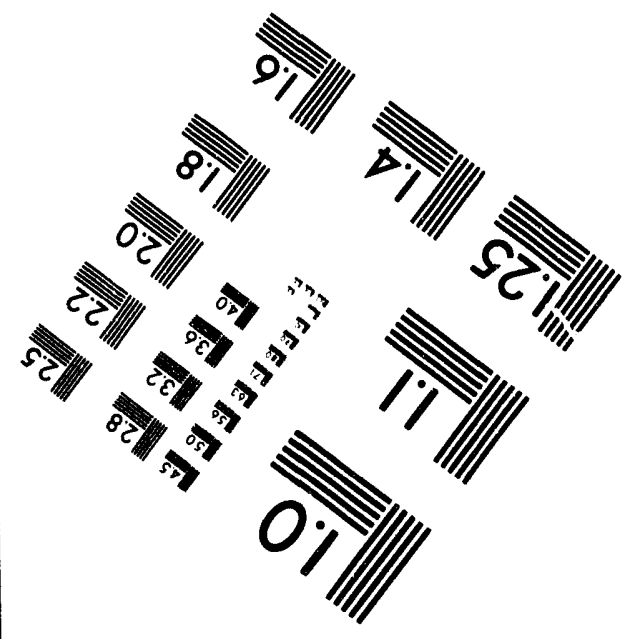

MANUFACTURED TO AIIM STANDARDS

BY APPLIED IMAGE. INC.

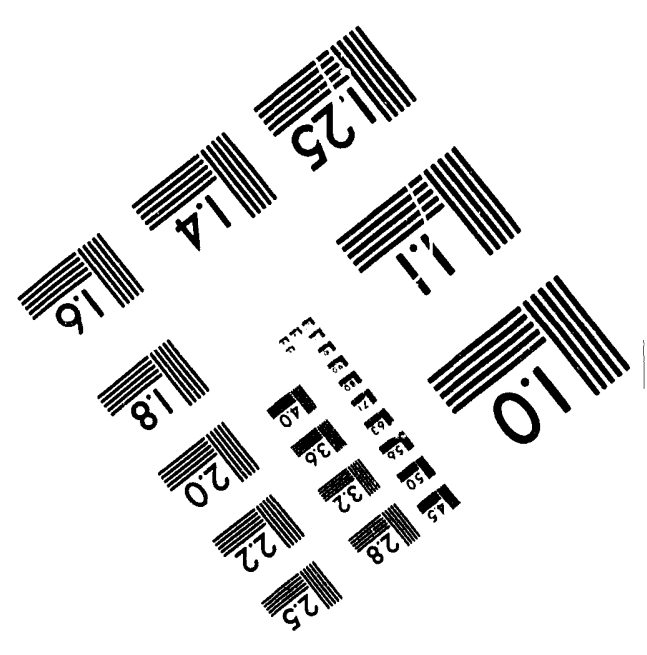



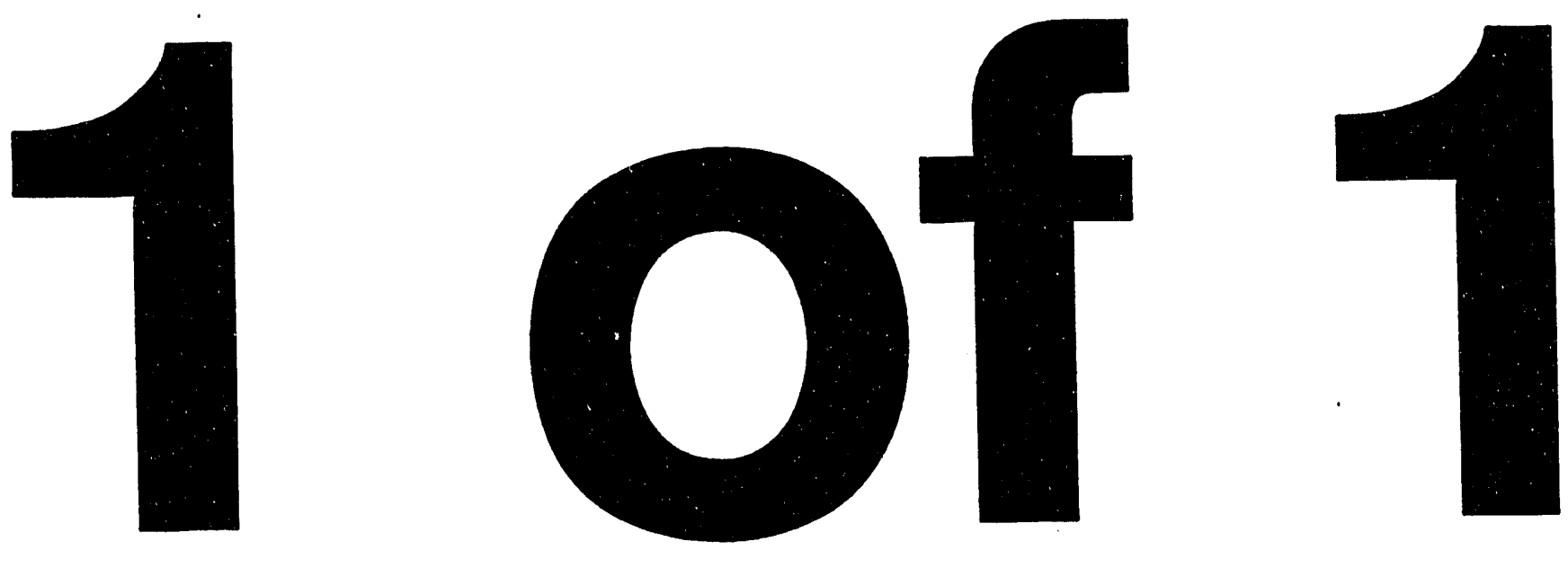
EGG 11265-1063

\title{
HERPETOLOGICAL REVIEW
}

\author{
Evaluation of a New Miniature Temperature Data Logger
}

James M. Mueller and Danny L. Rakestraw

EG\&G Energy Measurements, Inc., P.O. Box 1912, Las Vegas, Nevada

\section{5, USA}

\section{DISCLAIMER}

This report was prepared as an account of work sponsored by an agency of the United States Government. Neither the United States Government nor any agency thereof, nor any of their employees, makes any warranty, express or implied, or assumes any legal liability or responsibility for the accuracy, completeness, or usefulness of any information, apparatus, product, or process disclosed, or represents that its use would not infringe privately owned rights. Reference herein to any specific commercial product, process, or service by trade name, trademark, manufacturer, or otherwise does not necessarily constitute or imply its endorsement, recommendation, or favoring by the United States Government or any agency thereof. The views and opinions of authors expressed herein do not necessarily state or reflect those of the United States Government or any agency thereof. 
Peterson and Dorcas (1994) described the advantages of using data loggers to measure variation in the environment. We used a new, miniature temperature data logger to measure the temperatures of nests and hibernacula of desert tortoises (Gopherus agassizii). Here we report on the accuracy, reliability, and ease of use of these data loggers. Reference to a company or product name does not imply approval or recommendation of the product by the U.S. Department of Energy to the exclusion of others that may be suitable. Quoted costs are from a published price list.

We obtained 30 reusable, temperature data loggers (Hobo-Temp, Onset Computer Corporation, Pocasset, Mass.; cost $\$ 99.00$ ea.), each weighing $28 \mathrm{~g}$ and contained in a cylindrical plastic case that was $3.3 \mathrm{~cm}$ in diameter and 5.3 $\mathrm{cm}$ long. Measurable temperature range was -39 to $123^{\circ} \mathrm{C}$, although other standard and custom ranges were available. We chose to use internal thermistors, though units with an external thermistor were available for an additional $\$ 18.00$ per unit. Each data logger could store 1800 measurements in nonvolatile memory. The data loggers could be programmed to measure temperature at 31 possible time intervals ranging from 0.5 second to 4.8 hours with corresponding durations of measurement of 15 minutes to 360 days. We used DOS and Windows versions of program BOXCAR and a package of DOS programs called HOBO-PC (cost $\$ 49.00$ ea.) to set sampling duration and 
other options and to download data. Data loggers were connected to a computer using a 9-pin to 3.5-mm stereo-jack cable (cost \$9.00).

We tested the accuracy of the data loggers at $10^{\circ} \mathrm{C}$ intervals from -20 to $40^{\circ} \mathrm{C}$ using an oven (Delta Design, model 3900) and a calibrated thermometer (Instrulab, model 4202 , system accuracy ${ }^{\circ} 0.04^{\circ} \mathrm{C}$ within tested range). Accuracy averaged $0.34^{\circ} \mathrm{C}\left(\mathrm{SD}=0.23^{\circ} \mathrm{C}\right)$ with a maximum error of $1.03^{\circ} \mathrm{C}$. The data loggers were within manufacturer's specifications on $96 \%$ of the measurements, and the maximum deviation from the specifications was $0.2^{\circ} \mathrm{C}$.

We used the data loggers in the field to measure temperatures of desert tortoise nests and hibernacula. In January 1993, we glued data loggers to the carapaces of three hibernating tortoises that were near their hibernacula entrances. We set the data loggers to record temperatures every 1.2 hours for a duration of 90 days. We placed glue on the data logger case and then pressed the case against the carapace without moving the tortoise. We pried the data loggers from the carapace of each animal after it left its hibernaculum.

We placed 23 data loggers in desert tortoise nests at depths of 3-24 cm during May-July 1993 to measure nest temperatures. We programmed these units to record temperatures every 1.6 hours for a duration of 122 days.

We judged the reliability of the data loggers based on whether all data were acquired by each data logger. No data loggers placed on tortoises or in nests 
failed.

We judged ease of use of the software subjectively. All programs were simple to use and worked well. We found that the delayed start-up option was not ideal because the time recorded by the data logger automatically started at midnight of 1 January 1980 and had to be corrected after the data were downloaded. If the start time and date were not recorded, this information was lost. For this reason, we preferred using a laptop or handheld computer to start data loggers in the field. We had to ensure the computer's internal clock was accurate since that is where the data loggers obtained the start time and date.

We preferred using the Windows version of BOXCAR when first learning how to start-up and download data loggers. However, we preferred using the programs included with HOBO-PC when starting-up or downloading many data loggers or to translate many files to a spreadsheet format because options could be set using a batch file. This reduced the chance of selecting an incorrect option.

We found the Hobo-Temp to be a reliable and easy-to-use temperature data logger. A new, smaller, rectangular case $(4.5 \mathrm{~cm} \times 3.2 \mathrm{~cm} \times 1.5 \mathrm{~cm})$ may increase the range of potential applications. In addition, similar products are available for measuring relative humidity, light intensity, voltage, pressure, 
and vibration. We hope that our experience with this product will allow others to determine if a similar-type product could be useful in their research.

Acknowledgements.---This work was funded by the U.S. Department of Energy, Yucca Mountain Site Characterization Project, under contract No. DEAC08-93NV11265. Permission to handle desert tortoises was granted by the U.S. Fish and Wildlife Service through permits PRT-683011 and PRT-781234 and by the Nevada Division of Wildlife under permits S 6941 and S 9060 . We thank Kurt Rautenstrauch, Tom O'Farrell, Kent Ostler for reviewing this manuscript.

By acceptance of this article, the publisher and/or recipient acknowledges the U.S. Government's right to retain a nonexclusive royalty-free license in and to any copyright covering this paper. 


\section{Literature Cited}

Peterson, C. R., and M. E. Dorcas. 1994. Automated data acquisition. In W. R. Hyer, M. A. Donnelly, R. W. McDiarmid, L. C. Hayek, L. C. Hayek, and M. S. Foster (eds.), Measuring and Monitoring Biological Diversity: Standard Methods for Amphibians, pp. 47-56. Smithsonian Institution Press, Blue Ridge Summit, Pa. 

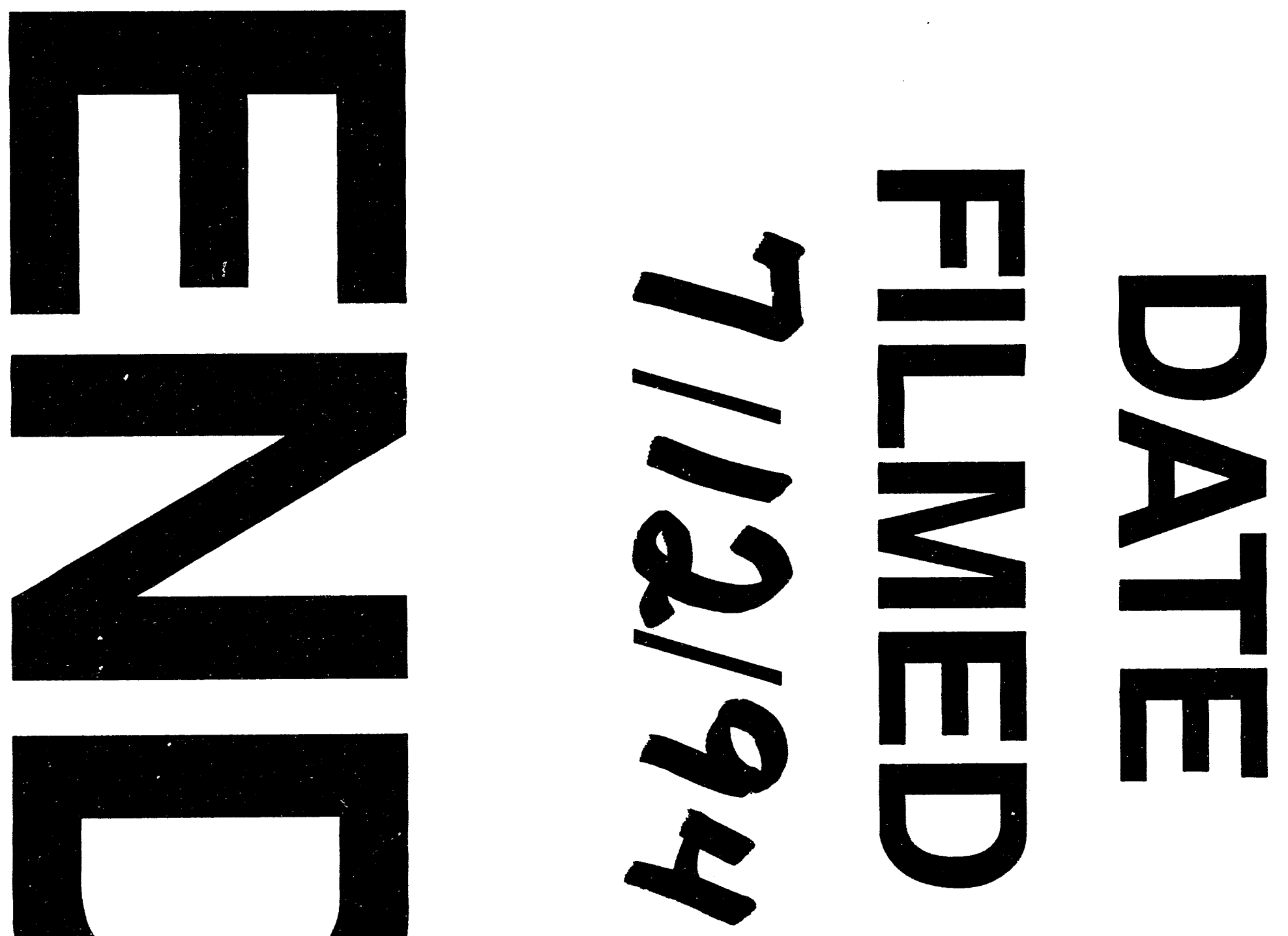

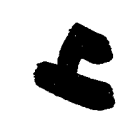


